\title{
SINCRONIZAÇÃO DO CICLO CELULAR EM MERISTEMA RADICULAR DE BARU (Dipteryx alata Vog.)
}

\author{
GIOVANA AUGUSTA TORRES \\ LISETE CHAMMA DAVIDE ${ }^{2}$ \\ EDUARDO BEARZOTI ${ }^{3}$
}

\begin{abstract}
RESUMO - Uma das dificuldades de se conduzir estudos citogenéticos em espécies vegetais nativas do cerrado é a ocorrência de baixos índices metafásicos no meristema radicular. O incremento dos índices mitótico e metafásico em células de pontas de raiz tem sido obtido em várias espécies com a sincronização do ciclo celular por meio de hidroxiuréia (HU). Neste trabalho foram determinadas as condições ótimas para a sincronização eficiente do ciclo em células meristemáticas de raízes de baru (Dipteryx alata Vog.). Foram testadas quatro concentrações de $\mathrm{HU}(0,00 ; 1,25$; 2,50; 5,00 e 10,00 mM), três tempos de exposição das
\end{abstract}

raízes $(10,15$ e 20 h) e dois tempos de recuperação do ciclo $(5$ e $10 \mathrm{~h})$. As melhores respostas foram obtidas com exposição das raízes, de cerca de $1 \mathrm{~cm}$, à solução de HU 3,5 $\mathrm{mM}$, por 20 horas, com posterior recuperação do ciclo em água destilada por 5 horas. $\mathrm{O}$ índice de $45 \%$ de células em divisão representou um incremento de cerca de 5 vezes em relação à testemunha, ao passo que para células em metáfases, o índice de $22,6 \%$ foi cerca de 10 vezes superior. Portanto, o uso dessa estratégia mostrou-se bastante eficiente para a obtenção de grande quantidade de cromossomos para análise citogenética do baru.

TERMOS PARA INDEXAÇÃO: Sincronização do ciclo celular, índice metafásico, índice mitótico, Dipteryx ala$t a$, hidroxiuréia, baru.

\section{SINCHRONIZATION OF CELL CYCLE IN ROOT MERISTEM OF BARU (Dipteryx alata Vog.)}

\begin{abstract}
A major difficulty in cytogenetic studies of plant species from "cerrado" is the low metaphasic index in root tip cells. Cell cycle synchronization, by using hydroxyurea (HU), has been successfully used in order to obtain high mitotic and metaphasic index in several species. The goal of this work was to optimize conditions for efficient synchronization of Dipteryx alata root tip meristematic cells. Different levels of hydroxyurea $(0,1.25,2.50$, 5.00 , and $10.00 \mathrm{mM})$, periods of treatment $(10,15$, and
\end{abstract}

$20 \mathrm{~h}$ ) and periods of cell cycle recovery (5 and $10 \mathrm{~h}$ ) were tested. Best results were achieved by treating 10 $\mathrm{mm}$ long roots with $3.5 \mathrm{mM}$ hydroxyurea, for $20 \mathrm{~h}$ and incubating for $5 \mathrm{~h}$ in distilled water. The amount of cells dividing was five folds increased, compared to that of the control treatment, reaching an index value of $45 \%$. Whereas for metaphase cells, the index value of $23 \%$ was 10 times higher. Therefore, such strategy was efficient to obtain high chromosome amounts for cytogenetic analysis of baru.

\section{INTRODUÇÃO}

O estudo citogenético de espécies vegetais do cerrado é bastante escasso, a despeito da reconhecida importância dessas informações para a inferência sobre a origem do bioma e sobre os processos envolvidos na evolução cariotípica de espécies tropicais (ForniMartins \& Martins, 2000). Uma das dificuldades encontradas no estudo de tais espécies é a baixa taxa de divisão celular encontrada nos meristemas radiculares

1. Engenheiro Agrônomo, DSc, Professora Adjunto do Departamento de Biologia da UNIVERSIDADE FEDERAL DE LAVRAS/UFLA - Caixa Postal 37 - 37200-000 - Lavras, MG.

2. Bióloga, DSc, Professora Titular do Departamento de Biologia da UFLA.

3. Engenheiro Agrônomo, DSc, Professor Adjunto do Departamento de Ciências Exatas da UFLA. 
das mesmas. Tal obstáculo é superado, em alguns casos, com o uso de agentes bloqueadores de mitose, que propiciam o acúmulo de células em metáfase, bem como a individualização dos cromossomos. No entanto, muitas vezes os índices metafásicos obtidos ainda não são satisfatórios para análises mais detalhadas, como é o caso do baru (Dipteryx alata Vog.), uma espécie arbórea da família Fabaceae.

Dentre as quinze espécies do gênero Dipteryx identificadas no Brasil, o baru é a única que ocorre no bioma cerrado, enquanto todas as outras, também arbóreas, ocorrem em florestas úmidas, especialmente na Amazônia. A descrição de seu complemento cromossômico, para posterior comparação com o das espécies presentes na Amazônia, traria grande contribuição para a discussão da relação cariotípica entre a flora dos dois biomas. Além disso, o baru apresenta elevado potencial econômico, graças à qualidade da madeira e elevado valor nutricional do fruto. Os estudos básicos, como os citogenéticos, trariam importantes subsídios para a manipulação eficiente da variabilidade observada para a espécie. Para tanto, é imprescindível a implementação de técnicas que permitam a obtenção de lâminas com maior quantidade de células em metáfase.

Altos índices mitóticos e metafásicos têm sido obtidos em células de ponta de raiz de várias espécies por meio de sincronização do ciclo celular com hidroxiuréia (HU). Esse composto inibe de forma reversível a produção de desoxiribonucleotídeos, impedindo a síntese de DNA e, portanto, bloqueando o ciclo na intérfase. Após remoção da HU, o ciclo prossegue normalmente, com um número elevado de células em sincronia (Pan et al., 1993).

O uso de tal estratégia, com posterior bloqueio da metáfase por diferentes agentes químicos, tem propiciado índices metafásicos de 50 a $70 \%$ em espécies como Zea mays L. (Lee et al., 1996), Triticum aestivum L. (Lee et al., 1997) e Pisum sativum L. (Gualberti et al., 1996). Além da alta quantidade dos cromossomos, esses apresentaram qualidade adequada para estudos de alta resolução, como citometria de fluxo, hibridização in situ e bandeamento cromossômico.

As condições otimizadas para as diversas espécies em que a sincronização foi usada foram bastante distintas no que diz respeito à concentração da hidroxiuréia, ao tempo de exposição das raízes e ao tempo de recuperação do ciclo. Isso se deve ao fato de a duração do ciclo celular, bem como de suas fases, variar bastante de uma espécie para outra (Clark \& Wall, 1996) e entre células do mesmo tecido meristemático (Clain \& Brulfert, 1980), e também à diferença de sensibilidade das espécies à hidroxiuréia. Assim, o sucesso da sincronização depende do ajuste desses fatores para cada espécie em que essa técnica for usada (Lee et al., 1996).

Neste trabalho, foram determinadas as condições ótimas para sincronização do ciclo de células meristemáticas de raízes de baru (Dipteryx alta Vog.), por meio de bloqueio reversível com hidroxiuréia, visando à obtenção de elevados índices metafásicos para análise citogenética da espécie.

\section{MATERIAL E MÉTODOS}

Sementes de baru (Dipteryx alata Vog.), provenientes de Jequitaí (norte do Estado de Minas Gerais), foram germinadas sobre papel de germinação (GERMILAB) constantemente umedecido com água destilada, em placas de Petri, a cerca de $29^{\circ} \mathrm{C}$, em estufa. Plântulas com radículas de tamanhos semelhantes, cerca de $1 \mathrm{~cm}$, foram transferidas para placas de Petri contendo soluções de hidroxiuréia nas concentrações 0 ; 1,$25 ; 2,5 ; 5,0$ e $10,0 \mathrm{mM}$, e incubadas a $29^{\circ} \mathrm{C}$, em estufa. Para cada concentração, as raízes foram submetidas aos períodos de exposição de 10, 15 e 20 horas. Após os diferentes períodos de exposição, as raízes foram lavadas em água corrente por 15 minutos, em água destilada por 5 minutos e transferidas para placa de Petri contendo um filme de água destilada, para recuperação do ciclo celular por 5 ou 10 horas.

Ao fim da recuperação, as raízes foram fixadas e posteriormente utilizadas para as preparações citológicas, seguindo técnicas usuais para o estudo de cromossomos de plantas. Assim, as raízes foram fixadas em solução gelada de metanol:ácido acético na proporção 3:1, por duas horas, a $-20^{\circ} \mathrm{C}$, com uma troca após os primeiros 30 minutos de fixação. Após a última troca, as raízes foram armazenadas em solução fixadora, a $20^{\circ} \mathrm{C}$, até o momento do uso. Para cada um dos tratamentos foram usadas duas raízes.

As raízes fixadas foram lavadas em água destilada por 10 min e submetidas à maceração enzimática em solução de celulase $2 \%$ - pectinase $20 \%$, em câmara úmida, por cerca de 2 horas, a $37^{\circ} \mathrm{C}$. Após remoção da solução enzimática, foi feita hidrólise das raízes em solução de $\mathrm{HCl} 1 \mathrm{~N}$, a $60^{\circ} \mathrm{C}$, por $10 \mathrm{~min}$. O meristema foi isolado e esmagado, sob lamínula, na presença de ácido acético $45 \%$. A lamínula foi retirada com o uso de nitrogênio líquido. Após secagem ao ar, as lâminas foram coradas com solução Giemsa 3\% (tampão fosfato $\mathrm{pH}$ 6,8 ), por cinco minutos, novamente secas ao ar e analisadas em microscópio de luz Olympus modelo BX 60, com aumento total de 200x. Em cada lâmina foram to- 
madas 200 células aleatoriamente, contando-se o número de células em metáfase e o número de células em divisão celular (prófase, metáfase, anáfase e telófase).

Os tratamentos foram definidos conforme uma estrutura fatorial 4 concentrações $\times 3$ tempos de exposição $\times 2$ tempos de recuperação. Um tratamento adicional foi considerado, correspondente a uma testemunha não submetida à hidroxiuréia. Esses 25 tratamentos foram dispostos em um delineamento inteiramente ao acaso com 2 repetições, e cada parcela correspondeu a uma lâmina contendo tecido meristemático de uma ponta de raiz diferente, da qual foram avaliadas 200 células.

As variáveis de resposta, número de células em divisão e em metáfase possuíam tipicamente uma distribuição de probabilidade binomial, ou seja: $\mathrm{Y}_{\mathrm{ijkl}} \sim \mathrm{b}(\mathrm{n}$, $\mathrm{p}_{\mathrm{ijk}}$ ), sendo $\mathrm{Y}_{\mathrm{ijkl}} \mathrm{o}$ número de células em metáfase (ou em divisão celular) observadas em lâmina montada com tecido submetido à concentração i de hidroxiuréia, no tempo de exposição j, período de recuperação $\mathrm{k}$ e repetição $1 ;$ n é o número de eventos (células) observados por lâmina, sempre igual a 200 , e $\mathrm{p}_{\mathrm{ijk}}$, a probabilidade de sucesso (metáfase ou divisão celular) correspondente à concentração i de hidroxiuréia, no tempo de exposição j, e período de recuperação k. Multiplicada por 100, tal probabilidade pode ser interpretada como a porcentagem esperada de células em divisão (índice mitótico) ou em metáfase (índice metafásico) sob determinado tratamento.

Por se tratar de uma distribuição binomial, optou-se por utilizar a teoria de modelos lineares generalizados (McCullagh \& Nelder, 1989), usando como função ligadora a função logística:

$$
\mathrm{p}_{\mathrm{ijk}}=\frac{\exp \left(\eta_{\mathrm{ijk}}\right)}{1+\exp \left(\eta_{\mathrm{ijk}}\right)}
$$

na qual "exp" é a função exponencial e $\eta_{\mathrm{ijk}}$ corresponde ao preditor linear, por sua vez dado por: $\eta_{\mathrm{ijk}}=\mu+\alpha_{\mathrm{i}}+$ $\beta_{\mathrm{j}}+\gamma_{\mathrm{k}}+(\alpha \beta)_{\mathrm{ij}}+(\alpha \gamma)_{\mathrm{ik}}+(\beta \gamma)_{\mathrm{jk}}+(\alpha \beta \gamma)_{\mathrm{ijk}}$, sendo $\mu$ uma constante comum a todas as observações; $\alpha_{i}$ o efeito da concentração i de hidroxiuréia; $\beta_{\mathrm{j}}$ o efeito do tempo $\mathrm{j}$ de exposição à hidroxiuréia; $\gamma_{\mathrm{k}} \mathrm{O}$ efeito do período de recuperação $\mathrm{k} ;(\alpha \beta)_{\mathrm{ij}} \mathrm{o}$ efeito da interação dupla entre a concentração i de hidroxiuréia e o tempo de exposição j; $(\alpha \gamma)_{\text {ik }}$ o efeito da interação dupla entre a concentração i de hidroxiuréia e o período de recuperação k; $(\beta \gamma)_{j \mathrm{k}} \mathrm{o}$ efeito da interação dupla entre o tempo de exposição j e o período de recuperação $\mathrm{k}$ e $(\alpha \beta \gamma)_{\mathrm{ijk}} \mathrm{o}$ efeito da interação tripla entre a concentração i de hidroxiuréia, o tempo de exposição j e o período de recuperação k.
A significância de tais efeitos foi testada utilizando a chamada "Análise de Deviance" (McCullagh \& Nelder, 1989). A estimação dos efeitos e a Análise de Deviance foram feitas utilizando o procedimento "genmod" do software SAS ${ }^{\circledR}$ (SAS Institute, 1993). Verificada a significância de algum dos termos da estrutura fatorial (fatores principais ou interações), o modelo era reparametrizado, construindo-se novos preditores correspondentes a moldelos de regressão múltipla. Para tanto, foi utilizado um procedimento de construção por etapas do tipo "backward" (Draper \& Smith, 1981). O preditor linear inicial submetido ao processo de "backward" foi dado por: $\eta_{i}=\left(\alpha_{0}+\beta_{0} Z_{i}\right)+\left(\alpha_{1} X_{i}+\beta_{1} X_{i}\right.$ $\left.\mathrm{Z}_{\mathrm{i}}\right)+\left(\alpha_{2} \mathrm{~W}_{\mathrm{i}}+\beta_{2} \mathrm{~W}_{\mathrm{i}} \mathrm{Z}_{\mathrm{i}}\right)+\left(\alpha_{3} \mathrm{X}_{\mathrm{i}}^{2}+\beta_{3} \mathrm{X}_{\mathrm{i}}^{2} \mathrm{Z}_{\mathrm{i}}\right)+\left(\alpha_{4} \mathrm{~W}_{\mathrm{i}}^{2}\right.$ $\left.+\beta_{4} \mathrm{~W}_{\mathrm{i}}^{2} \mathrm{Z}_{\mathrm{i}}\right)+\left(\alpha_{5} \mathrm{X}_{\mathrm{i}} \mathrm{W}_{\mathrm{i}}+\beta_{5} \mathrm{X}_{\mathrm{i}} \mathrm{W}_{\mathrm{i}} \mathrm{Z}_{\mathrm{i}}\right)+\left(\alpha_{6} \mathrm{X}_{\mathrm{i}}^{3}+\beta_{6}\right.$ $\left.\mathrm{X}_{\mathrm{i}}^{3} \mathrm{Z}_{\mathrm{i}}\right)++\left(\alpha_{7} \mathrm{X}_{\mathrm{i}}^{2} \mathrm{~W}_{\mathrm{i}}+\beta_{7} \mathrm{X}_{\mathrm{i}}^{2} \mathrm{~W}_{\mathrm{i}} \mathrm{Z}_{\mathrm{i}}\right)+\left(\alpha_{8} \mathrm{X}_{\mathrm{i}} \mathrm{W}_{\mathrm{i}}^{2}+\beta_{8}\right.$ $\left.\mathrm{X}^{2} \mathrm{~W}_{\mathrm{i}}^{2} \mathrm{Z}_{\mathrm{i}}\right)$, no qual $\alpha_{\mathrm{j}}$ e $\beta_{\mathrm{j}}(\mathrm{j}=1,2 \ldots 8)$ são parâmetros a serem estimados em cada etapa; $X_{i}$ é a concentração de hidroxiuréia referente à observação $\mathrm{i} ; \mathrm{W}_{\mathrm{i}}$ é o tempo de exposição à hidroxiuréia referente à observação i, e $\mathrm{Z}_{\mathrm{i}}$ é uma variável indicadora, assumindo valor 0 , caso a observação i correspondesse ao período de recuperação de 5 horas, e o valor 1, caso a observação i correspondesse ao período de recuperação de 10 horas.

Substituindo o preditor na função ligadora logística, foi possível obter superfícies de resposta da freqüência esperada de células em divisão e de células em metáfase, em função da concentração de hidroxiuréia e do tempo de exposição.

No tocante ao tratamento correspondente à testemunha, um intervalo de confiança exato para a probabilidade de sucesso da distribuição binomial (Blyth, 1986) foi construído para comparar a frequiência esperada de células em divisão do tratamento-testemunha com os demais.

\section{RESULTADOS E DISCUSSÃO}

Na Tabela 1 verifica-se a análise de deviance referente à proporção de células em divisão e em metáfase, considerando as parametrizações: modelo fatorial e regressão múltipla.

Para a variável número de células em divisão, o valor da deviance do modelo completo (resíduo) foi relativamente elevado $(41,7350)$, sendo significativo a $5 \%$ de probabilidade. Altas deviances podem ser indicativas de que a pressuposição quanto à distribuição de probabilidade (no presente caso, a binomial) não está perfeitamente atendida, resultando no fenômeno da superdispersão (Hinde \& Demétrio, 1998). No entanto, uma vez que o teste de qui-quadrado correspondente é assintóti-

Ciênc. agrotec., Lavras. V.27, n.2, p.398-405, mar./abr., 2003 
co, em geral, esse aspecto só é relevado em face de valores muito elevados de deviance, acima de duas vezes o número de graus de liberdade. Uma vez que isso não foi observado, os modelos ajustados foram tidos como satisfatórios. A deviance do modelo completo (resíduo) correspondente ao número de células em metáfase foi não significativa, significando que os modelos ajustados foram satisfatórios.

Pode-se observar na Tabela 1 que, para o número de células em divisão, a interação envolvendo todos os três fatores do modelo fatorial foi significativa, sugerindo que os níveis de cada fator só devam ser comparados fixando-se os níveis dos dois outros fatores. Para o número de células em metáfase, houve interação significativa apenas entre os fatores concentração e tempo de exposição à hidroxiuréia, inferindo-se que os níveis de cada fator só devam ser comparados fixando-se os níveis do outro fator.
A causa de variação "falta de ajustamento", ou "desvios de regressão", foi não significativa para os dois modelos de regressão múltipla ajustados, indicando a adequação dos mesmos. Na Tabela 2 verificam-se as estimativas dos 11 parâmetros dos modelos de regressão múltipla selecionados pelo método de "backward" para as variáveis número de células em divisão e em metáfase. Considerando os parâmetros retidos no primeiro modelo, observa-se uma coerência em relação à significância da interação tripla (Tabela 1), uma vez que há termos envolvendo produtos entre a concentração e o tempo de exposição à hidroxiuréia, bem como vários termos contendo a variável indicadora Z. Esse último aspecto faz com que duas superfícies de resposta não paralelas sejam necessárias para descrever a proporção de células em divisão, conforme o período de recuperação.

TABELA 1 - Análises de deviance referentes à proporção de células em divisão e de células em metáfase, considerando duas parametrizações correspondentes aos modelos fatorial e de regressão múltipla ${ }^{1}$.

\begin{tabular}{|c|c|c|c|}
\hline \multirow[t]{2}{*}{ Causas de Variação } & \multirow[t]{2}{*}{$\begin{array}{c}\text { Graus de } \\
\text { Liberdade }\end{array}$} & \multicolumn{2}{|c|}{$\begin{array}{c}\text { Qui-Quadrado } \\
\left(\chi^{2}\right)\end{array}$} \\
\hline & & Células em Divisão & Células em Metáfase \\
\hline \multicolumn{4}{|c|}{ (modelo fatorial) } \\
\hline Concentração & 3 & $399,5279 * *$ & $290,9741 * *$ \\
\hline Exposição & 2 & $11,7286^{* *}$ & 4,9608 \\
\hline Recuperação & 1 & 0,4043 & $15,2288^{* *}$ \\
\hline Conc $\times$ Expo & 6 & $84,0188 * *$ & $18,3250 * *$ \\
\hline Conc $\times$ Recup & 3 & 1,6264 & 5,7730 \\
\hline Expo $\times$ Recup & 2 & 2,9462 & 1,6648 \\
\hline Conc $\times$ Expo $\times$ Recup & 6 & $15,9244 *$ & 5,7287 \\
\hline \multicolumn{4}{|c|}{ (modelo de regressão) } \\
\hline Regressão & 11 & $521,8020 * *$ & $340,7390 * *$ \\
\hline Falta de Ajustamento & 12 & 9,8890 & 9,9657 \\
\hline Deviance (Resíduo) & 24 & $41,7350^{*}$ & 35,0653 \\
\hline
\end{tabular}

1: Testes de qui-quadrado são do tipo III (parciais) no modelo fatorial, e do tipo I (seqüenciais) no modelo de regressão.

**, *: significância ao nível de $1 \%$ e $5 \%$, respectivamente. 
No caso das células em metáfase, o fato de a interação tripla não ter sido significativa indica que as superfícies com períodos de recuperação 5 e 10 horas são semelhantes ou, se diferentes, pelo menos são paralelas. Em virtude dessa última possibilidade, optou-se por também utilizar a variável indicadora " $Z$ ", no modelo de regressão múltipla, à semelhança do que foi feito para a característica células em divisão. Assim, cada superfície poderia ser claramente caracterizada em cada período de recuperação. Na Tabela 2 verifica-se no modelo ajustado para a proporção de células em metáfase a existência de termos envolvendo o produto entre a concentração e o tempo de exposição à hidroxiuréia, em coerência com a significância observada da interação entre esses dois fatores (Tabela 1). Por outro lado, existem 4 parâmetros retidos que contêm produto de pelo menos um dos fatores acima com a variável indicadora $Z$, ao contrário do que seria de se esperar, a julgar pela não-significância da interação tripla (Tabela 1).

Comparando-se os dois modelos apresentados na Tabela 2, observa-se que a maioria dos parâmetros retidos são comuns. Essa semelhança é compreensível, dado que parte das células em divisão são células em metáfase.
Na Figura 1 são vistas as superfícies de resposta da proporção de células em divisão e de células em metáfase em função da concentração e tempo de exposição à hidroxiuréia, respectivamente para os períodos de recuperação de 5 e 10 horas. Pode-se observar que a concentração de HU exerceu grande efeito no poder bloqueador dessa substância. Essa interação já foi descrita em trabalhos nos quais o ciclo celular foi avaliado por citometria de fluxo, após exposição a diferentes concentrações de HU. Em Pisum sativum, Gualberti et al. (1996) verificaram que as concentrações de 5 e $10 \mathrm{mM}$ inibiam completamente a síntese de DNA, enquanto nas concentrações de 1,25 e 2,5 mM, um grupo grande de células tendiam a sair conjuntamente do bloqueio, propiciando uma sincronização eficiente. Na sincronização de células de milho (Lee et al., 1996), as concentrações de 1,25 e 2,5 mM foram ineficientes, enquanto a de 10 $\mathrm{mM}$ reteve as células no estágio $\mathrm{G}_{1}$ por um período muito longo de tempo, atrasando a transição para a fase S. Já para o trigo, a concentração de $2,5 \mathrm{mM}$ foi alta demais, dificultando a reversibilidade do bloqueio (Lee et al., 1997).

TABELA 2 - Estimativas dos parâmetros retidos no modelo de regressão múltipla após o processo de backward, para explicar os efeitos da concentração de hidroiuréia e do tempo de exposição nos períodos de recuperação de 5 e 10 horas na proporção de células em divisão e células em metáfase em baru .

\begin{tabular}{ccccc}
\hline Parâmetro & Estimativa & Qui-Quadrado & Estimativa & Qui-Quadrado \\
\cline { 2 - 4 } Intercepto & \multicolumn{2}{c}{ Células em Divisão } & \multicolumn{2}{c}{ Células em Metáfase } \\
Z & $-6,5517$ & $319,3261^{* *}$ & $-6,7029$ & $223,9861^{* *}$ \\
X & 2,7956 & $23,5262^{* *}$ & 2,1414 & $8,1540^{* *}$ \\
X Z & 3,0143 & $219,9689^{* *}$ & 2,6665 & $93,1507^{* *}$ \\
X $^{2}$ & $-1,1893$ & $26,3288^{* *}$ & $-0,7191$ & $5,6926^{*}$ \\
X $^{2}$ Z & $-0,5364$ & $154,9997^{* *}$ & $-0,4975$ & $68,5690^{* *}$ \\
X $^{3}$ & 0,0914 & $23,7480^{* *}$ & 0,0531 & $4,2125^{*}$ \\
W & 0,0295 & $126,9116^{* *}$ & 0,0274 & $57,4157^{* *}$ \\
W Z & 0,1260 & $60,6230^{* *}$ & 0,0677 & $17,3495^{* *}$ \\
X W & $-0,1797$ & $25,7814^{* *}$ & $-0,1308$ & $8,0508^{* *}$ \\
X W Z & $-0,0202$ & $47,7225^{* *}$ & 0,0463 & $6,3695^{*}$ \\
X W Z & 0,0757 & $28,6430^{* *}$ & $-0,0012$ & $7,8046^{* *}$ \\
\hline
\end{tabular}

1. $X$ : concentração de hidroxiuréia; $W$ : tempo de exposição à hidroxiuréia; $Z$ : variável indicadora para discriminar os períodos de recuperação (valor 0: 5 horas; valor 1: 10 horas).

**, *: significância ao nível de $1 \%$ e $5 \%$, respectivamente.

Ciênc. agrotec., Lavras. V.27, n.2, p.398-405, mar./abr., 2003 
Para as células meristemáticas do baru, esses resultados mostram que as concentrações abaixo de 2,5 $\mathrm{mM}$ não foram eficientes no bloqueio do ciclo, enquanto as superiores a $5 \mathrm{mM}$ foram muito drásticas. Nesse último caso, provavelmente seria necessário um período de recuperação superior a 10 horas, o que não foi avaliado neste trabalho, ou poderia ter ocorrido bloqueio irreversível do ciclo.

A concentração em que se esperam os índices máximos foi obtida atribuindo-se o valor 20 ao tempo de exposição, uma vez que esse período de exposição correspondeu à resposta máxima nas quatro superfícies da Figura 1, resultando em uma equação dependente apenas da concentração. Derivando-se essa equação em relação a essa variável, e igualando-se a zero, pode-se

A

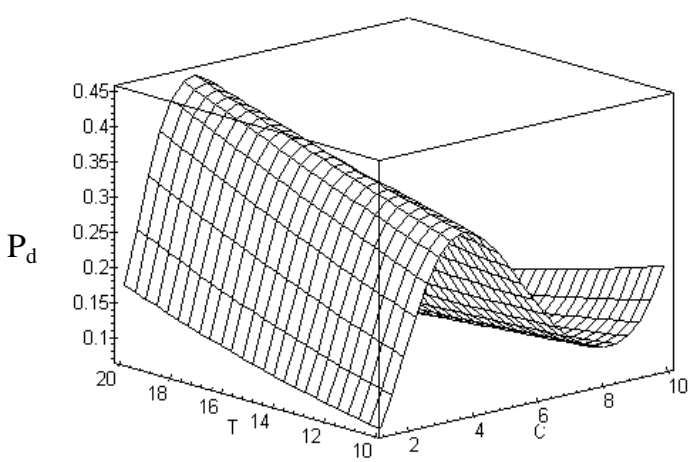

C

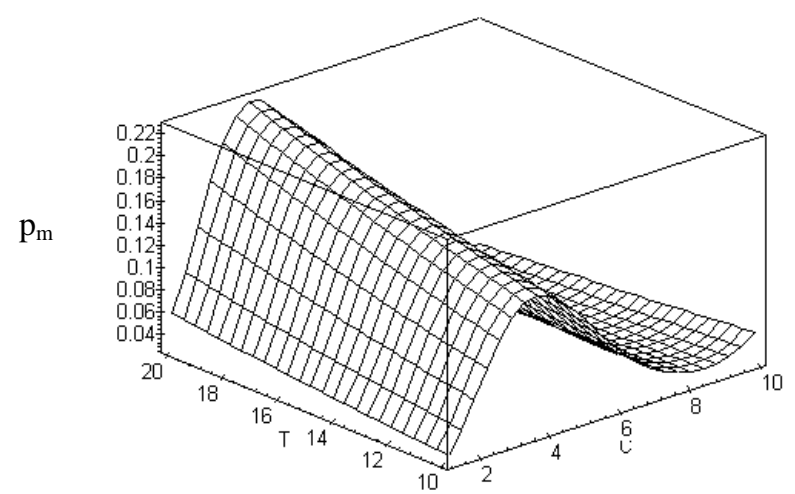

tomar o ponto crítico correspondente ao ponto de máximo.

Sob o período de recuperação de 5 horas (Figura 1A), a concentração estimada de $3,37 \mathrm{mM}$ foi a que propiciou maior índice mitótico, $45,1 \%$. Com o período de recuperação de 10 horas (Figura 1B), o ponto de máximo estimado correspondeu à concentração de $3,72 \mathrm{mM}$, com a qual espera-se $46,8 \%$ de células em divisão. A reposta máxima esperada quanto ao índice metafásico $(22,6 \%)$, para o período de recuperação de 5 horas (Figura 1C), ocorreu com a concentração estimada de $3,55 \mathrm{mM}$. Com o período de recuperação de 10 horas (Figura 1D), as grandezas acima foram, respectivamente, iguais a $25,7 \%$ e 3,87 $\mathrm{mM}$.

B

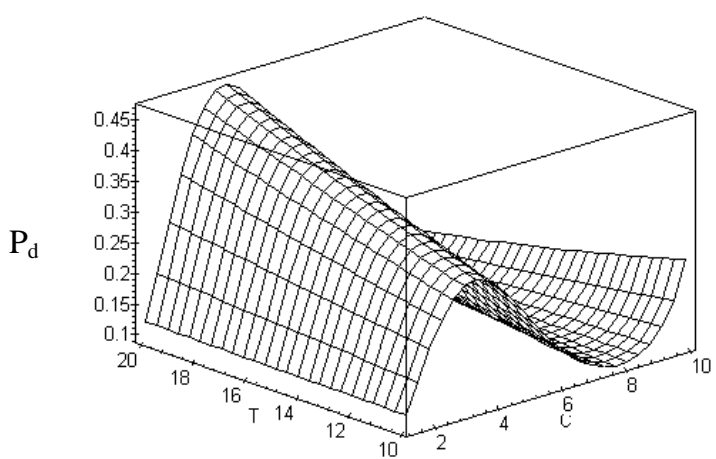

D

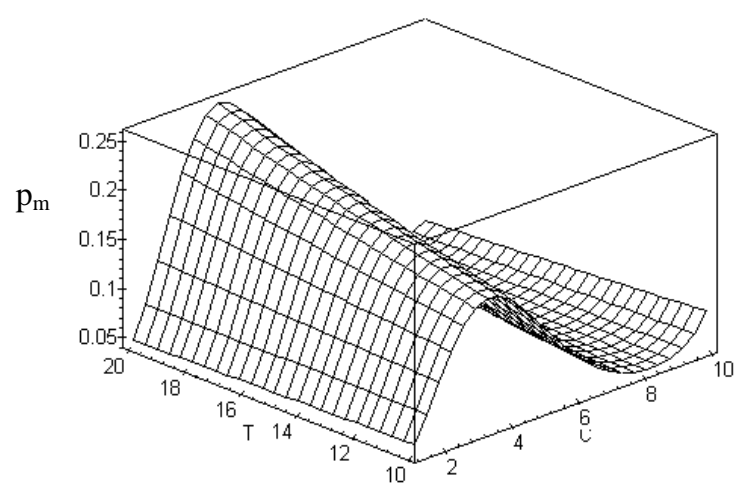

FIGURA 1 - Superfícies de resposta, em função da concentração $(C)$ e tempo de exposição $(\mathrm{T})$ à hidroxiuréia, da proporção de células em divisão $\left(\mathrm{p}_{\mathrm{d}}\right)$, para os períodos de recuperação de 5 horas $(\mathrm{A})$ e 10 horas $(\mathrm{B})$ e da proporção de células em metáfase $\left(\mathrm{p}_{\mathrm{m}}\right)$, para os períodos de recuperação de 5 horas (C) e 10 horas (D). 
As raízes que não foram submetidas à hidroxiuréia apresentaram um índice mitótico médio de $8,75 \%$, compreendido no intervalo de confiança $(\gamma=0,95)$ : [0,0617;0,1196], e índice metafásico médio de 2,5\%, compreendido no intervalo de confiança $(\gamma=0,95)$ : $[0,0121 ; 0,0455]$. Comparando esses valores com as respostas esperadas com uso da hidroxuréia, em concentrações próximas de $3,5 \mathrm{mM}$, verifica-se que os incrementos nos índices mitótico e metafásico foram da ordem de 5 e 10 vezes, respectivamente. Isso indica que a sincronização é uma estratégia eficiente para a sincronização do ciclo celular e obtenção de elevado número de células meristemáticas de baru em metáfase.

A sincronização mostrou-se mais eficiente à medida que o tempo de exposição aumentou, e a resposta máxima em ambos os casos ocorreu para o período de exposição de 20 horas, ou seja, o maior testado. Isso é compreensível quando se considera que a sincronia natural é bastante baixa e o período maior permite que uma quantidade maior de células atinja a fase $S$ da interfase, onde serão bloqueadas. Apesar de o resultado indicar que um maior tempo de exposição poderia aumentar os índices obtidos, tal estratégia poderia trazer prejuízo à qualidade dos cromossomos, uma vez que exposições superiores a 24 horas podem causar aberrações devido a quebras cromossômicas, acompanhadas por uma troca irreversível de cromátides irmãs, ou distúrbio do mecanismo de reparo do DNA (Anderson, 1983).

Com relação ao tempo de recuperação do ciclo, os valores máximos esperados para os tempos de 5 e 10 horas foram bastante semelhantes para os dois índices. Esses dois picos indicam que a sincronização se deu em duas populações de células, em diferentes estágios, uma vez que o intervalo de 5 horas entre o primeiro pico e o segundo é muito pequeno para que um novo ciclo se completasse em um único grupo de células. Dessa forma, o período mais curto, 5 horas, é mais vantajoso, uma vez que traz redução no tempo necessário para a aplicação da metodologia.

O número de células em metáfase, de grande interesse para análise citogenética, poderá ainda ser aumentado com a utilização de substâncias antimitóticas, após o bloqueio do ciclo celular com hidroxiuréia. Tal estratégia, denominada sincronização em duas etapas, propiciou índices metafásicos de cerca de $50 \%$ em duas espécies do gênero Larix, com uso de colchicina (Nkongolo \& Klimaszewska, 1995) e em aveia, trigo, centeio e Melandrium album Garcke, com uso de amiprofosmetila (Pan et al., 1992).

\section{CONCLUSÕES}

A hidroxiuréia é uma substância eficiente para a sincronização do ciclo celular de células meristemáticas do baru (Dipteryx alata Vog.), quando radículas são submetidas, por um período de 20 horas, a uma solução $3,5 \mathrm{mM}$, com posterior recuperação do ciclo por 5 horas em água destilada, propiciando índices metafásicos bastante satisfatórios para análise citogenética.

\section{REFERÊNCIAS BIBLIOGRÁFICAS}

ANDERSON, H. D. Hydroxyurea induces sister chromatid exchanges in G2: implications for the formation of chromosomal aberrations. Hereditas, Lund, v. 98, p. 61-64, 1983.

BLYTH, C. R. Approximate binomial confidence limits. Journal of the American Statistical Association, Washington, v. 81, n. 395, p. 843-855, 1986.

CLAIN, E.; BRULFERT, A. Hydroxyurea-induced mitotic synchronization in Allium sativum root meristems. Planta, Berlin, v. 150, p. 26-31, 1980.

CLARK, M. S.; WALL, W. J. Chromosomes: the complex code. London: Chapman \& Hall, 1996. 345 p.

DRAPER, N. R.; SMITH, H. Applied Regression Analysis. New York: John Wiley, 1981. 709 p.

FORNI-MARTINS, E. R.; MARTINS, F. R. Chromosome studies on Brazilian cerrado plants. Genetics and Molecular Biology, Ribeirão Preto, v. 23, n. 4, p. 947956, 2000.

GUALBERTI, G.; DOLEZEL， J.; MACAS， J.; LUCRETTI, S. Preparation of pea (Pisum sativum L.) chromosomes and nucleus suspensions from single root tips. Theoretical and Applied Genetics, Belfast, v. 92, p. 744-751, 1996.

HINDE, J.; DEMÉTRIO, C. G. B. Overdispersion: models and estimation. São Paulo: Associação Brasileira de Estatística, 1998. 73 p.

LEE, J.; ARUMUGANATHAN, K.; KAEPPLER, S. M.; KAEPPLER, H. F.; PAPA, C. M. Cell synchronization and isolation of metaphase chromosomes from maize (Zea mays L.) root tips for flow cytometric analysis and sorting. Genome, Ottawa, v. 39, p. 697703, 1996. 
LEE, J.; ARUMUGANATHAN, K.; YEN, Y.; KAEPPLER, S. M.; KAEPPLER, H. F.; BAENZIGER, P. S. Root tip cell synchronization and metaphasechromosome isolation suitable for flow sorting in common wheat (Triticum aestivum L.). Genome, Ottawa, v. 40, p. 633-638, 1997.

McCULLAGH, P.; NELDER, J. Generalized linear models. London: Chapman and Hall, 1989.

NKONGOLO, K. K.; KLIMASZEWSKA, K. Cytological and molecular relationships between Larix de- cidua, L. leptolepis and Larix $\mathrm{x}$ eurolepis: identification of species-specific chromosomes and synchronization of mitotic cells. Theoretical and Apllied Genetics, Belfast, v. 90, p. 827-834, 1995.

PAN, W. H.; HOUBEN, A.; SCHLEGEL, R. Highly effective cell synchronization in plant roots by hydroxyurea and amiprophos-methyl or colchicine. Genome, Ottawa, v. 36, p. 387-390, 1993.

SAS INSTITUTE. SAS/STAT ${ }^{\circledR}$ : user's guide. Volume 6.4. Cary, 1993. 